\title{
METODOLOGIA DE INVESTIGAÇÃO CIENTÍFICA APLICADA À GESTÃO AMBIENTAL: UM ESTUDO SOBRE AS ABORDAGENS QUALITATIVA E QUANTITATIVA
}

\author{
Manuel Pastor Francisco Conjo ${ }^{1}$ \\ David Benjamim Chichango ${ }^{2}$ \\ Paulo de Paula e Souza ${ }^{3}$
}

RESUMO: Diante dos actuais desafios sociais e ambientais que o desenvolvimento encontra, é preciso pesquisar, conceber, avaliar e aplicar diferentes modelos de investigação em gestão ambiental. Diversos enfoques teóricos e metodológicos são necessários para superar as visões econômicas predominantes que se revelaram restritivas em termos de compreensão da complexidade socioambiental que leva ao agravamento de problemas de deterioração do meio ambiente e de exclusão social, o que directa e indirectamente acaba por se reflectir nas condições de vida dos seres humanos. A pesquisa científica possui diversas modalidades, cada uma delas desenvolvida por um ou mais métodos e técnicas de pesquisa. Entre suas modalidades de pesquisa, existem duas abordagens que abrangem outras formas de pesquisar: a pesquisa de abordagem qualitativa e a pesquisa de abordagem quantitativa. Neste estudo, veremos essas duas modalidades, suas aplicações e diferenças, além da possibilidade de interligação entre as duas. $O$ trabalho que apresentamos resulta de uma revisão bibliográfica cujo objectivo geral é compreender o que é pesquisa qualitativa e pesquisa quantitativa. São objectivos específicos descrever as abordagens qualitativa e quantitativa, caracterizar as duas abordagens, e apresentar os métodos e técnicas de pesquisa aplicados em cada uma das abordagens. Realizado o estudo, os resultados mostram que a pesquisa qualitativa preocupa-se com o significado dos fenômenos e processos sociais, levando em consideração as motivações, crenças, valores e representações encontradas nas relações sociais, por meio de interpretação e explicação dos fenómenos e a pesquisa quantitativa preocupa-se com a quantificação dos dados, comprovando se uma teoria é válida ou não a partir de análises estatísticas.

Palavras - Chave: Metodologia. Pesquisa qualitativa. Pesquisa quantitativa.

\footnotetext{
I Doutorando em Ciência Florestal pela Universidade Federal de Viçosa - Minas Gerais - Brasil. Mestrado em Gestão Ambiental pela Universidade Pedagógica de Maputo - Moçambique.Bacharel e Licenciado em Ensino de Geografia pela Universidade Pedagógica de Maputo - Moçambique. Técnico Superior em Higiene e Segurança no Trabalho e Meio Ambiente pela Ensine Moçambique. E-mail: m.conjo@hotmail.com.

2 Mestrando em Gestão Ambiental, Faculdade de Ciências da Terra e Ambiente, Universidade Pedagógica de Maputo. Prof de Geografia, Licenciado em Ensino de Geografia, Faculdade de Ciências da Terra e Ambiente, Universidade Pedagógica de Maputo, Moçambique., Moçambique. E-mail: davidchitlhango@gmail.com

3 Mestrando em Gestão Ambiental, Faculdade de Ciências da Terra e Ambiente, Universidade Pedagógica de Maputo. Gestor. Licenciado em Gestão e Direito Privado. Unirsity of South Africa. Pos-Graduação em Administração de Empresas, University of South Africa., Moçambique.E-mail: ppsouza@hotmail.com.
} 
ABSTRACT: Given the current social and environmental challenges that development faces, it is necessary to research, design, evaluate and apply different models of research in environmental management. Several theoretical and methodological approaches are needed to overcome the prevailing economic views that have proved to be restrictive in terms of understanding the socio-environmental complexity that leads to aggravating problems of environmental deterioration and social exclusion, which directly and indirectly end up being reflected in the living conditions of human beings.Scientific research has several modalities, each one developed by one or more research methods and techniques. Among its research modalities, there are two approaches that cover other forms of research: qualitative approach research and quantitative approach research. In this study, we will see these two modalities, their applications and differences, as well as the possibility of interconnection between the two. The work we present is the result of a literature review whose general objective is to understand what qualitative and quantitative research is. Specific objectives are to describe the qualitative and quantitative approaches, characterize the two approaches, and present the research methods and techniques applied in each of the approaches. After the study, the results show that qualitative research is concerned with the meaning of social phenomena and processes, taking into account the motivations, beliefs, values and representations found in social relationships, through interpretation and explanation of phenomena and research. quantitative is concerned with quantifying data, proving whether a theory is valid or not based on statistical analyses.

Keywords: Methodology. Qualitative research. Quantitative research.

I CONTEXTUALIZAÇÃO

Para FONSECA (2002), metodologia é o estudo da organização, dos caminhos a serem percorridos, para se realizar uma pesquisa ou um estudo, ou para se fazer ciência. Etimologicamente, significa o estudo dos caminhos, dos instrumentos utilizados para fazer uma pesquisa científica.

A metodologia se interessa pela validade do caminho escolhido para se chegar ao fim proposto pela pesquisa; portanto, não deve ser confundida com o conteúdo (teoria) nem com os procedimentos (métodos e técnicas). Dessa forma, a metodologia vai além da descrição dos procedimentos (métodos e técnicas a serem utilizados na pesquisa), indicando a escolha teórica realizada pelo pesquisador para abordar o objecto de estudo (MINAYO, 2007:44).

MINAYO (2007), define metodologia de forma abrangente como a discussão epistemológica sobre o "caminho do pensamento" que o tema ou o objecto de investigação requer; como a apresentação adequada e justificada dos métodos, técnicas e dos instrumentos operativos que devem ser utilizados para as buscas 


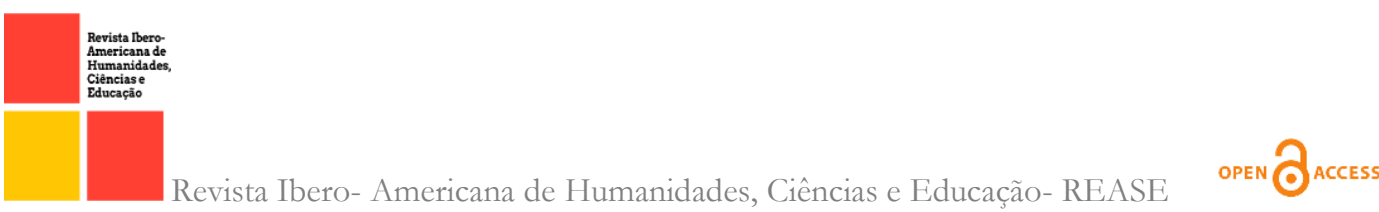

relativas às indagações da investigação; e como a "criatividade do pesquisador", ou seja, a sua marca pessoal e específica na forma de articular teoria, métodos, achados experimentais, observacionais ou de qualquer tipo específico de resposta às indagações específicas.

Diante dos actuais desafios sociais e ambientais que o desenvolvimento encontra, as ciências ambientais são desafiadas a pesquisar, conceber, avaliar e aplicar diferentes modelos de investigação em gestão ambiental. Diversos enfoques teóricos e metodológicos são necessários para superar as visões económicas predominantes que levaram ao agravamento de problemas de deterioração do meio ambiente e de exclusão social; o que directa e indirectamente acaba por se reflectir nas condições de vida dos seres humanos.

A pesquisa científica em gestão ambiental possui diversas modalidades, cada uma delas desenvolvida por um ou mais métodos e técnicas de pesquisa. Entre suas modalidades de pesquisa, existem duas abordagens que abrangem outras formas de pesquisar: a pesquisa de abordagem qualitativa e a pesquisa de abordagem quantitativa. Neste estudo, veremos essas duas modalidades, suas aplicações e diferenças, além da possibilidade de interligação entre as duas. $O$ trabalho que apresentamos resulta de uma revisão bibliográfica cujo objectivo geral é compreender o que é pesquisa qualitativa e pesquisa quantitativa. São objectivos específicos descrever as abordagens qualitativa e quantitativa, caracterizar as duas abordagens, e apresentar os métodos e técnicas de pesquisa aplicados em cada uma das abordagens.

\section{MATERIAIS E MÉTODOS}

Para o alcance dos objectivos traçados neste estudo, foi aplicada a pesquisa bibliográfica, ou de fontes secundárias, que de acordo com LAKATOS e MARCONI (2003), abrange toda bibliografia já tornada pública em relação ao tema de estudo, desde publicações avulsas, boletins, jornais, revistas, livros, pesquisas, monografias, teses, material cartográfico etc., até meios de comunicação orais: rádio, gravações em fita magnética e audiovisuais: filmes e televisão.

Deste modo, foram analisados diversos materiais constantes da bibliografia final, que abordam os conteúdos que fazem corpo deste estudo. 


\section{RESULTADOS}

\section{I A PESQUISA QUALITATIVA}

\subsection{Génese da metodologia de abordagem qualitativa}

A gênese do aspecto qualitativo da pesquisa está na crítica do positivismo, através, por exemplo, de Max Weber. Muitas vezes, sob o título de pesquisa qualitativa, "encontram-se variados tipos de investigação, apoiados em diferentes quadros de orientação teórica e metodológica, tais como a etnografia, o materialismo histórico e a fenomenologia " (GODOY, 1995:6I), apud (FERREIRA, 2015)

De acordo com MINAYO (2001:14), a pesquisa qualitativa foi aplicada inicialmente em estudos de Antropologia e Sociologia, como contraponto à pesquisa quantitativa dominante, e alargado seu campo de actuação a áreas como a Psicologia e a Educação.

A pesquisa qualitativa é criticada por seu empirismo, pela subjectividade e pelo envolvimento emocional do pesquisador (MINAYO, 2001:14).

\subsubsection{Características da metodologia de abordagem qualitativa}

A abordagem qualitativa na pesquisa possui algumas características básicas, comentadas por GODOY (1995: 62-63), tais como:

- O estudo empírico é realizado no seu ambiente natural, pois os factos sociais têm que ser observados e analisados inseridos no contexto ao qual pertencem, através de contacto directo,

- O pesquisador desempenha um papel fundamental na observação, selecção, consolidação e análise dos dados gerados;

- Os dados existentes na realidade são considerados importantes para a compreensão do fenômeno social em estudo,

- O pesquisador realiza entrevistas, reúne fotografias, desenhos e depoimentos e outros dados que ajudam na descrição do facto;

- O trabalho é realizado com base na perspectiva que as pessoas pesquisadas têm sobre o objecto de estudo,

- Deve-se primar pela fidedignidade dos dados obtidos; 
- A análise dos dados computados é feita de forma indutiva e, ao longo dela, dá-se a construção paulatina do quadro teórico, sem a formulação de uma hipótese anterior que precisa ser testada com a pesquisa.

- A perspectiva qualitativa na pesquisa possibilita ao pesquisador desvelar e interpretar a fala dos entrevistados, pois, fornece uma compreensão profunda de certos fenômenos sociais apoiados no pressuposto da maior relevância do aspecto subjectivo da acção social face à configuração das estruturas societais” (HAGUETTE, 1992), apud (GODOY 1995: 620)

A pesquisa qualitativa busca entender fenômenos humanos, buscando deles obter uma visão detalhada e complexa por meio de uma análise científica do pesquisador. Esse tipo de pesquisa se preocupa com o significado dos fenômenos e processos sociais. É uma análise relacionada também à subjectividade, que leva em consideração as motivações, crenças, valores e representações encontradas nas relações sociais (KNECHTEL, 2014).

Deste modo a análise qualitativa é essencial para o entendimento da realidade humana, das dificuldades vivenciadas, das atitudes e dos comportamentos dos sujeitos envolvidos, constituindo-se um suporte teórico essencial bastante aplicável em pesquisas de Gestão Ambiental em busca de solução para os problemas ambientais que que afectam o nosso planeta rumo ao desenvolvimento sustentável.

(CASSEL e SYMON, 1994:127 - I29) apud (DALFOVO, et al, 2008), apresentam as seguintes características da metodologia qualitativa:

- Um foco na interpretação ao invés de na quantificação: geralmente, o pesquisador qualitativo está interessado na interpretação que os próprios participantes tem da situação sob estudo;

- Ênfase na subjetividade ao invés de na objetividade: aceita-se que a busca de objetividade é um tanto quanto inadequada, já que o foco de interesse é justamente a perspectiva dos participantes;

- Flexibilidade no processo de conduzir a pesquisa: o pesquisador trabalha com situações complexas que não permite a definição exata e apriori dos caminhos que a pesquisa irá seguir; d) orientação para o processo e não para o resultado: a ênfase está no entendimento e não num objectivo pré determinado, como na pesquisa quantitativa; 
- Preocupação com o contexto, no sentido de que o comportamento das pessoas e a situação ligam-se intimamente na formação da experiência;

- Reconhecimento do impacto do processo de pesquisa sobre a situação de pesquisa: admite-se que o pesquisador exerce influência sobre a situação de pesquisa e é por ela também influenciada. (CASSEL e SYMON, 1994:127 I29) apud (DALFOVO, et al, 2008)

Segundo KNECHTEL, (2014), os pressupostos básicos da pesquisa qualitativa são:

- A preocupação primária com os processos, não se preocupando diretamente com o resultado e o produto; o interesse pelo significado, como as pessoas relatam suas vivências e experiências, sua visão de mundo; a busca por informações diretamente no campo de pesquisa;

- A ênfase na descrição e explicação de fenômenos; a utilização de processos indutivos, a fim de construir conceitos, hipóteses e teorias.

KNECHTEL (2014:IOI-IO2), apresenta as principais características da pesquisa qualitativa:

- Ressalta a natureza socialmente construída da realidade;

- Relação entre o pesquisador e o objecto de estudo;

- Ênfase nas qualidades e nos processos, com destaque para a forma como a experiência social é criada e adquire significado;

- Utiliza entrevistas e observação detalhada (métodos interpretativos);

- Estuda casos específicos;

- Valoriza as descrições detalhadas;

- Faz uso de narrativas históricas, materiais biográficos e autobiográficos (KNECHTEL, 2014:IOI-IO2).

A pesquisa qualitativa não se preocupa com representatividade numérica, mas, sim, com o aprofundamento da compreensão de um grupo social, de uma organização. Os pesquisadores que adotam a abordagem qualitativa opõem-se ao pressuposto que defende um modelo único de pesquisa para todas as ciências, já que as ciências sociais têm sua especificidade, o que pressupõe uma metodologia própria. $\mathrm{Na}$ pesquisa qualitativa o pesquisador tem o ambiente como fonte de busca de dados, podendo envolver-se directamente na pesquisa. 


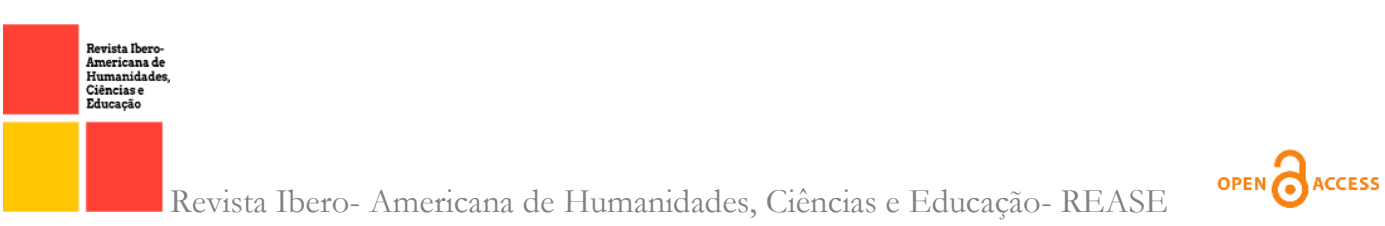

Assim, os pesquisadores qualitativos recusam o modelo positivista aplicado ao estudo da vida social, uma vez que o pesquisador não pode fazer julgamentos nem permitir que seus preconceitos e crenças contaminem a pesquisa (GOLDENBERG, 1997:34), apud (GERHARDT e SILVEIRA, 2009).

De acordo com GERHARDT e SILVEIRA (2009), os pesquisadores que utilizam os métodos qualitativos buscam explicar o porquê das coisas, exprimindo o que convém ser feito, mas não quantificam os valores e as trocas simbólicas nem se submetem à prova de factos, pois os dados analisados são não-métricos.

$\mathrm{Na}$ pesquisa qualitativa, o cientista é ao mesmo tempo o sujeito e o objecto de suas pesquisas. $\mathrm{O}$ conhecimento do pesquisador é parcial e limitado. O objectivo da amostra é de produzir informações aprofundadas e ilustrativas: seja ela pequena ou grande, o que importa é que ela seja capaz de produzir novas informações (DESLAURIERS, I991:58), apud (GERHARDT e SILVEIRA, 2009).

Segundo MINAYO (200I), a pesquisa qualitativa preocupa-se, portanto, com aspectos da realidade que não podem ser quantificados, centrando-se na compreensão e explicação da dinâmica das relações sociais.

A pesquisa qualitativa trabalha com o universo de significados, motivos, aspirações, crenças, valores e atitudes, o que corresponde a um espaço mais profundo das relações, dos processos e dos fenômenos que não podem ser reduzidos à operacionalização de variáveis (MINAYO, 200I).

Para GERHARDT e SILVEIRA, (2009), as características da pesquisa qualitativa são: objectivação do fenômeno; hierarquização das acções de descrever, compreender, explicar, precisão das relações entre o global e o local em determinado fenômeno; observância das diferenças entre o mundo social e o mundo natural; respeito ao caráter interativo entre os objetivos buscados pelos investigadores, suas orientações teóricas e seus dados empíricos; busca de resultados os mais fidedignos possíveis; oposição ao pressuposto que defende um modelo único de pesquisa para todas as ciências.

Buscando entender, compreender, explicar e descrever com precisão os problemas ambientais de um determinado local, a metodologia qualitativa apresentase como uma opção a se aplicar trazendo um conjunto de linhas de orientações nesta perspectiva. 
Entretanto, (GERHARDT e SILVEIRA, 2009) explicam que:

O pesquisador deve estar atento para alguns limites e riscos da pesquisa qualitativa, tais como: excessiva confiança no investigador como instrumento de colecta de dados; risco de que a reflexão exaustiva acerca das notas de campo possa representar uma tentativa de dar conta da totalidade do objecto estudado, além de controlar a influência do observador sobre o objecto de estudo; falta de detalhes sobre os processos através dos quais as conclusões foram alcançadas; falta de observância de aspectos diferentes sob enfoques diferentes; certeza do próprio pesquisador com relação a seus dados; sensação de dominar profundamente seu objeto de estudo; envolvimento do pesquisador na situação pesquisada, ou com os sujeitos pesquisados. (GERHARDT e SILVEIRA, 2009)

As pesquisas qualitativas, descrevem a complexidade de determinado problema, sendo necessário compreender e classificar os processos dinâmicos vividos nos grupos, contribuir no processo de mudança, possibilitando o entendimento das mais variadas particularidades dos indivíduos. A pesquisa qualitativa não é passível de ser medida em escala numérica. (ROSENTAL; 200I).

Este método difere, em princípio, do quantitativo, à medida que não emprega um instrumental estatístico como base na análise de um problema, não pretendendo medir ou numerar categorias (RICHARDSON, 1989), apud (DALFOVO et al, 2008).

TESCH, (1990), explica:

Os estudos de campo qualitativos não tem um significado preciso em qualquer área onde sejam utilizados. Para alguns, todos os estudos de campo são necessariamente qualitativos e, mais ainda, como já comentado, identificam-se com a observação participante. Podemos partir do princípio de que a pesquisa qualitativa é aquela que trabalha predominantemente com dados qualitativos, isto é, a informação colectada pelo pesquisador não é expressa em números, ou então os números e as conclusões neles baseadas representam um papel menor na análise. Dentro de tal conceito amplo, os dados qualitativos incluem também informações não expressas em palavras, tais como pinturas, fotografias, desenhos, filmes, vídeo tapes e até mesmo trilhas sonoras (TESCH, 1990), apud (DALFOVO et al, 2008)

Segundo DEMO (2013), as pesquisas qualitativas são participantes, pesquisa acção, histórica, oral, fenomenológica, análises de grupos, entre outras. É um tipo de pesquisa que procura abrir novas perspectivas de observação.

Infelizmente, para DALFOVO et al (2008), a pesquisa qualitativa não tem ainda o papel de destaque que deveria ter. Muitos pesquisadores a evitam, em nome de uma pretensa neutralidade científica e de um rigor metodológico mais próprio da ciência natural. 
Para DALFOVO et al (2008), algumas características dos estudos qualitativos são:

- Os dados são colectados preferencialmente nos contextos em que os fenômenos são construídos;

- A análise de dados é desenvolvida, de preferência, no decorrer do processo de levantamento destes;

- Os estudos apresentam-se de forma descritiva, com enfoque na compreensão à luz dos significados dos próprios sujeitos e de outras referências;

- A teoria é construída por meio de análise dos dados empíricos, para posteriormente ser aperfeiçoada com a leitura de outros autores;

- A interação entre pesquisador e pesquisado é fundamental, razão pela qual se exige do pesquisador diversos aperfeiçoamentos, principalmente em técnicas comunicacionais. (DALFOVO et al, 2008)

As características principais deste método são a intensidade, a flexibilidade e a medida qualitativa (FIGUEIREDO, 2017).

\subsubsection{Etapas da pesquisa qualitativa}

Para ALVES (1991), apud FERREIRA (2015), três importantes momentos devem ser levados em consideração, quando se opta por esta abordagem qualitativa:

a) A fase de exploração da pesquisa,

b) A fase da investigação;

c) A análise dos resultados finais e elaboração do texto final.

\subsubsection{Métodos apropriados à abordagem qualitativa}

Evidentemente, existem alguns métodos mais apropriados a tal colecta e análise: entrevistas abertas, observação participante, análise documental (cartas, diários, impressos, relatórios, etc.), estudos de caso, história de vida, etc. (DALFOVO et al, 2008)

Para FIGUEIREDO (2017), a pesquisa qualitativas pode aplicar a observação empírica semi-estruturada ou não estruturada, observação participante, entrevistas semi-estruturadas/semi-centradas, entrevista não estruturada/em profundidade, histórias de vida/ biografias e análise qualitativa de conteúdo de documentos. 
Métodos de carácter mais qualitativo, como estudo de casos, também designado por análise intensiva, que consiste no exame intensivo, tanto em amplitude como em profundidade, utilizando todas as técnicas disponíveis de uma amostra particular, seleccionada de acordo com determinado objectivo, de um fenómeno social, organizando os dados de forma a preservar o carácter unitário da amostra. Tudo isto com a finalidade de obter uma ampla compreensão do fenómeno na sua totalidade (FIGUEIREDO, 2017).

\subsection{A PESQUISA QUANTITATIVA 3.2.1. Génese da pesquisa quantitativa}

A pesquisa quantitativa, que tem suas raízes no pensamento positivista lógico, tende a enfatizar o raciocínio dedutivo, as regras da lógica e os atributos mensuráveis da experiência humana. Por outro lado, a pesquisa qualitativa tende a salientar os aspectos dinâmicos, holísticos e individuais da experiência humana, para apreender a totalidade (POLIT, BECKER e HUNGLER, 2004:20I), apud (GERHARDT e SILVEIRA, 2009)

De acordo com FERREIRA (2015), origem do quantitativismo está associada à filosofia da ciência, com Galileu e Newton, e está presente na linha de pensamento empirista e positivista.

A pesquisa quantitativa está ligada directamente à quantificação dos dados, na experimentação, na mensuração e no controle rigoroso dos factos.

Segundo KNECHTEL (2014), a pesquisa quantitativa foi a base do pensamento científico até a metade do século XX e é caracterizada pela passividade e neutralidade do pesquisador diante da investigação da realidade.

“A principal influência do positivismo foi a utilização dos termos de tipo matemático para a compreensão da realidade e a linguagem de variáveis para especificar atributos e qualidade do objecto de investigação" (HUGHES: 1987 apud MINAYO, 1996:23).

WILSON (1986), apud GERHARDT e SILVEIRA, (2009), afirma que, de acordo com o ponto de vista de quantitativistas, uma pesquisa só terá validade científica, se der margem à classificação, testagem de hipótese, medição e tabulação, não revelando nenhum aspecto significativo dos fenômenos sociais. 


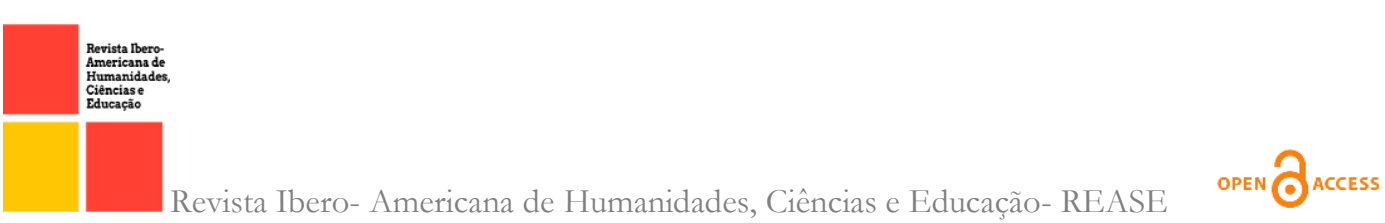

Para KNECHTEL (2014), a pesquisa quantitativa tem por base a quantificação dos dados e busca medir opiniões e informações utilizando os recursos da estatística, como a percentagem, a média, o desvio-padrão.

Os dados quantitativos, são valores observados de um conjunto de variáveis, que podem representar alguns elementos ou todos os elementos, por exemplo, de uma sociedade, de uma determinada população. Tais dados são apresentados em forma de tabelas, gráficos ou textos (KNECHTEL, 2014).

MINAYO (1996), argumenta:

A grande questão em relação à quantificação na análise sociológica é a sua possibilidade de esgotar o fenômeno social. Corre-se o risco de que um estudo de alto gabarito do ponto de vista matemático ou estatístico, em que toda a atenção se concentre na manipulação sofisticada dos instrumentos de análise - portanto, competente do ponto de vista estatístico - despreze aspectos essenciais da realidade. E muitas vezes teremos uma 'resposta exacta' para 'perguntas erradas ou imprecisas (MINAYO, 1996:30), apud (FERREIRA 2015)

Para os pesquisadores que defendem a linha quantitativa, o aspecto qualitativo tem natureza subjectiva - imprópria para o fazer científico, portanto essas características devem ser removidas do processo de pesquisa através de abordagens que envolvam o caráter qualitativo (WILSON, I986), apud (FERREIRA, 2015)

FONSECA (2002:20), explica que os resultados da pesquisa quantitativa podem ser quantificados. Como as amostras geralmente são grandes e consideradas representativas da população, os resultados são tomados como se constituíssem um retrato real de toda a população alvo da pesquisa.

A pesquisa quantitativa se centra na objectividade. Influenciada pelo positivismo, considera que a realidade só pode ser compreendida com base na análise de dados brutos, recolhidos com o auxílio de instrumentos padronizados e neutros. A pesquisa quantitativa recorre à linguagem matemática para descrever as causas de um fenômeno, as relações entre variáveis, etc (FONSECA, 2002:20).

Para KNECHTEL (2014), a pesquisa quantitativa é aplicada na realização de pesquisas sociais, econômicas, comunicação, mercadológicas, administrativas. É uma pesquisa ligada à investigação empírico-descritiva, quando se procura descobrir e classificar a relação entre as variáveis, as relações de causa e efeito entre os diferentes fenômenos. 


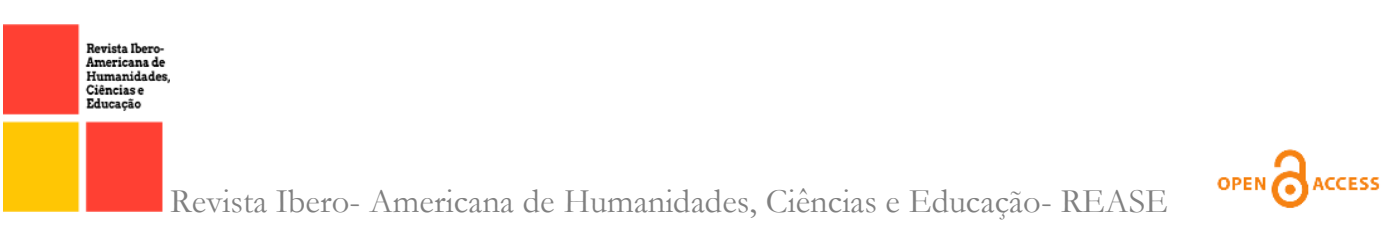

DIEHL (2004) apud (DALFOVO et al, 2008), apresenta um esboço acerca destas duas estratégias: a) a pesquisa quantitativa pela uso da quantificação, tanto na colecta quanto no tratamento das informações, utilizando-se técnicas estatísticas, objectivando resultados que evitem possíveis distorções de análise e interpretação, possibilitando uma maior margem de segurança.

\subsubsection{Características da metodologia quantitativa}

Seguindo ensinamentos de RICHARDSON (1989), apud DALFOVO et al, (2008), este método caracteriza-se pelo emprego da quantificação, tanto nas modalidades de colecta de informações, quanto no tratamento dessas através de técnicas estatísticas, desde as mais simples até as mais complexas (DALFOVO, et al, 2008).

Para KNECHTEL (2014), a pesquisa quantitativa é uma modalidade de pesquisa que actua sobre um problema humano ou social, é baseada no teste de uma teoria e composta por variáveis quantificadas em números, as quais são analisadas de modo estatístico, com o objectivo de determinar se as generalizações previstas na teoria se sustentam ou não.

A pesquisa quantitativa se preocupa com a quantificação dos dados, comprovando se uma teoria é válida ou não a partir de análises estatísticas.

Para DALFOVO et al, (2008), os estudos de campo quantitativos guiam-se por um modelo de pesquisa onde o pesquisador parte de quadros conceituais de referência tão bem estruturados quanto possível, a partir dos quais formula hipóteses sobre os fenômenos e situações que quer estudar.

Uma lista de consequências é então deduzida das hipóteses. A colecta de dados enfatizará números (ou informações conversíveis em números) que permitam verificar a ocorrência ou não das consequências, e daí então a aceitação (ainda que provisória) ou não das hipóteses. Os dados são analisados com apoio da Estatística (inclusive multivariada) ou outras técnicas matemáticas.

Os tradicionais levantamentos de dados são o exemplo clássico do estudo de campo quantitativo (POPPER, 1972), apud (ROSENTAL, 2010).

RICHARDSON (1989), citado por DALFOVO et al, (2008), expõe que este método é frequentemente aplicado nos estudos descritivos (aqueles que procuram 
descobrir e classificar a relação entre variáveis), os quais propõem investigar "o que é”, ou seja, a descobrir as características de um fenômeno como tal.

No planeamento deste tipo de estudo, o primeiro passo a ser dado é no sentido de identificar as variáveis específicas que possam ser importantes, para assim poder explicar as complexas características de um problema. (RICHARDSON, I989), apud (DALFOVO et al, 2008)

Outrossim, segundo RICHARDSON (1989), embora muitos experimentos em Ciências Sociais estejam limitados pelas características dos sujeitos, pelo instrumento de avaliação empregados, factor de tempo, disposição de pessoas, o que pode implicar grave incorreção é a grande tendência dos profissionais em fazer generalizações com base nos resultados dos experimentos (apud DALFOVO et al, 2008).

Em TRIPOLDI (1981:48), apud (DALFOVO et al, 2008), enquadra estudos quantitativos-descritivos como uma categoria dentro da pesquisa. Esta categoria, ainda possui sub-divisões, ou como cita o autor propósitos, bem como de modo geral a "verificação de hipóteses e a descrição de relações quantitativas entre variáveis especificadas".

O primeiro propósito se destina a hipóteses de causa-efeito ou então as hipóteses que inter relacionam duas ou mais variáveis. O segundo propósito serve para correlacionar várias variáveis específicas para responder as questões específicas da pesquisa.

Deste modo, na busca das relações causa-efeitos dos problemas ambientais, a metodologia quantitativa pode ser aplicada como forma de propor soluções para alguns problemas que afectam o ambiente incluindo o Homem. Outrossim, em conexão com a metodologia qualitativa, os dados colhidos no campo de pesquisa podem ser discutidos e analisados por meio de pacotes estatístico-matemáticos.

O autor TRIPOLDI (1981:5r) apud (DALFOVO et al, (2008), ressalta que características experimentais de busca aleatória e o trabalho em cima de variáveis independentes não podem fazer parte de estudos quantitativo-descritivos. A pesquisa classificada, desde que, se tenha controlo sobre as variáveis podem assumir papel importante em estudos quantitativo-descritivos. 


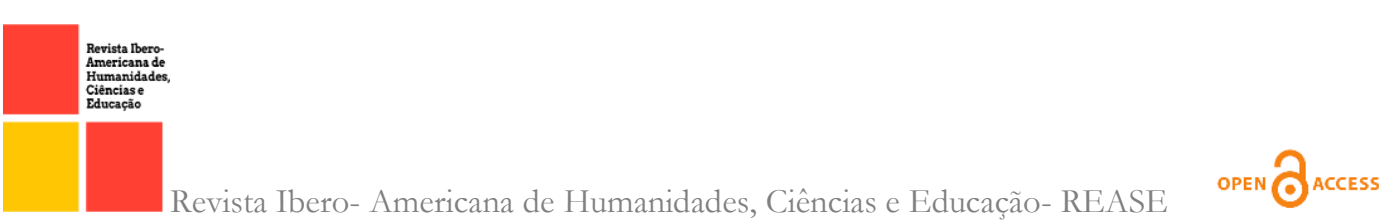

\subsubsection{Métodos e técnicas de pesquisa apropriados à abordagem quantitativa}

A colecta de dados geralmente é realizada nestes estudos por questionários e entrevistas que apresentam variáveis distintas e relevantes para pesquisa, que em análise é geralmente apresentado por tabelas e gráficos (TRIPOLDI, 1981:52), apud (DALFOVO et al, 2008).

Conforme MARCONI (1982), apud DALFOVO, et al (2008), a expressão dos dados pode ser abordada ao revelar que devem ser expressos com medidas numéricas. Defende ainda que técnicas quânticas de análise e tratamento dos dados apresentam melhor compreensão, mais objectivo, dinamizam o processo de relação entre variáveis.

Segundo FIGUEIREDO (2017), os métodos de carácter mais Quantitativo podem ser:

- Experimental, que implica vários momentos de observação, em condições semelhantes e a existência de grupos de teste e de grupos de controlo;

- De medida, que implica a observação, por meio de questões directas e/ou indirectas, de populações relativamente vastas, com o objectivo de obter respostas susceptíveis de serem manejadas mediante uma análise quantitativa;

- As características principais deste método são a extensividade, a rigidez e a quantificação (FIGUEIREDO, 2017).

Para FIGUEIREDO (2017), as técnicas de recolha de informação quantitativas implicam a observação empírica muito estruturada e relativamente rígida); questionário submetido ao tratamento estatístico dos dados em SPSS; entrevistas estruturadas/centradas submetidas ao tratamento quantitativo dos dados em SPSS; análise quantitativa de conteúdo de documentos e a experimentação.

Pois em MARCONI (1982) apud (DALFOVO, et al 2008), a pesquisa quantitativa também é apresentada como "semântica quantitativa e análise de conteúdo", trabalhando e mensurando dados de uma base textual.

\subsubsection{Base de informação da metodologia quantitativa}

As bases da informação na pesquisa quantitativa são classificadas em (KNECHTEL, 2014:93-95): 
Dados primários: obtidos no campo da pesquisa, diretamente com as fontes originais de informação (sujeitos respondentes e/ou entrevistados);

Dados secundários: dados já processados, normalmente vindos de pesquisas oficiais e/ou outras fontes credenciadas;

Experimento de Campo: o pesquisador promove alterações no campo de pesquisa para medir padrões de comportamento e de relação entre as variáveis (agricultura: teste com sementes);

Pesquisa descritiva: colecta de várias informações com grande número de variáveis, que serão reduzidas a quantificadores, que representam a dinâmica social, a fim de descrever o acontecimento dos fenômenos (pesquisa eleitoral e de mercado);

Pesquisa exploratória: aplica instrumentos para medir e descrever determinado comportamento social, que não possuía grande atenção da comunidade científica (pesquisas que verificam mudanças de padrões de comportamento social). (KNECHTEL, 2014:93-95):

A pesquisa quantitativa trabalha com dados colectados directamente no campo de investigação ou com dados já processados por outras fontes de pesquisa, que buscam quantificar a informação (KNECHTEL, 2014).

Quadro I- Metodologia de abordagem quantitativa: Vantagens e desvantagens

\begin{tabular}{|c|c|}
\hline \multicolumn{2}{|c|}{ Metodologia de abordagem quantitativa } \\
\hline Vantagens & Desvantagens \\
\hline $\begin{array}{l}\text { - Possibilitam a investigação e a descrição } \\
\text { de estruturas e processos sociais que } \\
\text { dificilmente são diretamente observáveis; } \\
\text { - Possibilitam uma muito mais fácil } \\
\text { quantificação dos dados e } \\
\text { consequentemente uma maior } \\
\text { comparação entre casos, uma maior } \\
\text { objetivação da informação recolhida e } \\
\text { respetiva análise; } \\
\text { - Facilitam a descrição da mudança, das } \\
\text { transformações; } \\
\text { - Analisam e explicam as dependências }\end{array}$ & $\begin{array}{l}\text { Simplificam demasiado a complexidade da } \\
\text { realidade; } \\
\text { - Só podem ser aplicados a fenómenos mensuráveis } \\
\text { (e quantificáveis); } \\
\text { - Pressupõe um conhecimento vasto e profundo } \\
\text { sobre o objecto de estudo, no sentido de poder } \\
\text { utilizar e perguntar as questões corretas (adequadas, } \\
\text { adptadas perfeitamente ao que se quer saber); } \\
\text { - Produz uma visão mais ou menos estática da } \\
\text { realidade, tornando difícil o estudo de fenómenos e } \\
\text { processos muito dinâmicos; } \\
\text { - Dado que, em geral, são utilizadas questões e }\end{array}$ \\
\hline
\end{tabular}


(causais) entre os fenómenos sociais;

- Permitem a recolha de informação de forma mais rápida $e$, frequentemente, mais fácil e menos dispendiosa;

- Permitem a recolha de informação junto de populações mais vastas. respostas muito rígidas, não têm em conta as descrições da realidade produzidas pelos inquiridos, as suas intenções e significados.

Fonte: FIGUEIREDO, (2017)

A utilização conjunta da pesquisa qualitativa e quantitativa permite recolher mais informações do que se poderia conseguir isoladamente

\section{CONSIDERAÇÕES FINAIS}

Realizado este estudo conclui-se que a pesquisa em Gestão Ambiental pode se aplicar de diversas maneiras sendo que a pesquisa qualitativa busca entender fenômenos humanos que podem interferir no meio ambiente, buscando deles obter uma visão detalhada e complexa por meio de uma análise científica do pesquisador através da descrição dos factos em estudo com envolvimento activo do pesquisador no trabalho de campo. Esse tipo de pesquisa preocupa-se com o significado dos fenômenos e processos sociais, levando em consideração as motivações, crenças, valores e representações encontradas nas relações sociais, por meio de interpretação e explicação dos fenómenos. A pesquisa quantitativa se preocupa com a quantificação dos dados, comprovando se uma teoria é válida ou não a partir de análises estatísticas. Os estudos de campo quantitativo guiam-se por um modelo de pesquisa onde o pesquisador parte de quadros conceituais de referência tão bem estruturados quanto possível, a partir dos quais formula hipóteses sobre os fenômenos e situações que quer estudar, com base em dados numéricos.

Porém, as relações entre abordagens qualitativas e quantitativas demonstram que as duas metodologias podem ser integradas num mesmo projecto, uma pesquisa quantitativa pode conduzir o investigador à escolha de um problema particular a ser analisado em toda sua complexidade, através de métodos e técnicas qualitativas e vice-versa e a investigação qualitativa é a que melhor se coaduna ao reconhecimento de situações particulares, grupos específicos e universos simbólicos. 


\section{REFERÊNCIAS BIBLIOGRÁFICAS}

ALVES, Alda. O Planejamento de Pesquisas Qualitativas em Educação. Cadernos de Pesquisa, São Paulo, n. 77, maio/1997

DALFOVO, Michael et al. Métodos quantitativos e qualitativos: um resgate teórico. Revista Interdisciplinar Científica Aplicada. Blumenau, v.2, n.4, p.oI- 13, Sem II. 2008 ISSN 1980-7031.

DEMO, Pedro. Metodologia do conhecimento científico. São Paulo: Atlas, 2013

FERREIRA, Carlos Augusto Lima. Pesquisa quantitativa e qualitativa: perspectivas para o campo da educação. Revista Mosaico, Goiânia, v. 8, n. 2, p. 173-ı82, jul./dez. 2015.

FONSECA, J. J. S. Metodologia da pesquisa científica. Fortaleza. UEC, 2002. Apostila. GODOY, Arilda Schmidt. Pesquisa Qualitativa - tipos fundamentais. Revista de Administração de Empresas. São Paulo. RAE, v. 35, p. 20-29, maio/jun. 1995.

KNECHTEL, Maria do Rosário. Metodologia da pesquisa em educação: uma abordagem teórico-prática dialogada. Curitiba. Inter saberes, 2014.

LAKATOS, Eva Maria e MARCONI, Marina de Andrade. Fundamentos de metodologia científica. 5ª Edição. São Paulo. Editora Atlas. 2003.

MINAYO, M. C. S. (Org.). Pesquisa social: teoria, método e criatividade. Petrópolis:

Vozes, 2001.

MINAYO, M. C. S. O desafio do conhecimento. Pesquisa qualitativa em saúde. São Paulo. HUCITEC, 2007.

ROSENTAL, Claude; FRÉMONTIER-MURPHY, Camille. Introdução aos métodos quantitativos em ciências humanas e sociais. Porto Alegre. Instituto Piaget. 2001. 